\title{
Ti İmplantların Biyofilim Engelleme Amaçlı Nano hBN - HA ile Kaplanmasının Yüzey Karaktersitiğine Etkisinin Belirlenmesi
}

\author{
Levent URTEKIN* \\ "Kırşehir Ahi Evran Üniversitesi, Makina Mühendisliği Bölümü, Kırşehir, \\ levent.urtekin@ahievran.edu.tr
}

Hicabi SEZGIN

Kırşehir Ahi Evran Üniversitesi, Tıp Fakültesi, Ortopedi Anabilim Dalı, Kırşehir, hicabi.sezgin@ahievran.edu.tr

\section{Ali SEVIM}

Kırşehir Ahi Evran Üniversitesi, Ziraat Fakültesi, Bitki Koruma Bölümü, Kırşehir, ali.sevim@ahievran.edu.tr

\section{Nuran AY}

Eskişehir Teknik Üniversitesi, Malzeme Bilimi ve Mühendisliği Bölümü, Eskişehir, nay@eskisehir.edu.tr

Geliş: 18.04.2020, Revizyon: 28.06.2020, Kabul Tarihi: 29.06.2020

\section{$\ddot{\mathbf{O z}}$}

Birçok metal alaşımı implant uygulamalarında geniş bir şekilde kullanılmaktadır. Bu metal alaşım yüzeylerine kolonize olan bakteriler implanta bağlı olarak enfeksiyon oluşturabilmektedir. Bu çalışmada implant yüzeyine hidroksiapatit ve nano hexogonal bornitrür ile kaplama yapllarak biyofilim ve buna bağll enfeksiyon oluşumunu engellemek amaçlı yüzey karakteristiği tayin edilmiştir. Kaplama sonrası yüzeyde oluşan pürüzlülük değişimi, sertlik değişimi ve SEM analizleri gerçekleştirilmiştir. Elde edilen biyo-yüzeyin Staphylococcus aureus bakterisine olan ilgisi araştırlmaya devam etmektedir.

Anahtar Kelimeler: Biyofilim, kaplama, implant, Ti alaşım

* Yazışmaların yapılacağı yazar

DOI: $10.24012 /$ dumf.722558 


\section{Giriș}

Travmatik kemik hasarının düzeltilmesi ortopedik cerrahi ile mümkündür. İyileşme süresi kırığa bağlı olarak değişir. $\mathrm{Bu}$ amaçla farklı implant materyalleri kemik kırığında kullanılmaktadır. Doğal insan kemik dokusuna en yakın organik ve inorganik maddelerden hidroksiapatitten yapılmıș kompozit malzeme tercih edilir. Bundan dolayı Hidroksiapatit (HA) ortopedik implantlarda yaygin olarak kullanılmaktadır. Kristal yapıya benzerliğinden dolayı kemik dokusu kusurlarının kimyasal olarak oluşması nedeniyle onarımı ve rekonstrüksiyonu HA ile mümkün olduğu çeşitli çalışmalarla gösterilmiştir. HA mükemmel biyo uyumluluk gösterir. Dezavantaj olarak ise ne yazık ki, HA ağır yüklemede kullanılamaz. Zayıf mekanik özelliklerinden dolayı çeşitli sıkıntılar meydana gelmektedir. HA kaplama, Titanyum ve alaşımları ve $316 \mathrm{~L}$ paslanmaz çeliklere uygulanmaktadır. Mekanik özellikleri (yüksek özgül mukavemet, kemik elastik modülü ile eşleşen düşük elastik modül doku) ve ayrıca yüksek korozyon direncine sahiptirler [1-6]. HA kompozit kaplama malzemelerini kaplamak için birçok teknik mevcuttur. Bunlar; daldırma kaplama, plazma spreyi, elektroforetik biriktirme, darbeli lazer püskürtme ve sol-jel işleme yöntemleridir. Bu kaplama teknikleri arasında çatlak içermeyen kaplamalar üretmek zor olsa da, elektroforetik biriktirme (EPD) yöntemi diğerlerine göre çeşitli avantajlara sahiptir. EPD kaplamanın kurulumda basitlik, düşük ekipman maliyeti, karmaşık şekil, birikim kalınlığının kontrolü kabiliyeti bulunmaktadır [7-8]. Birçok araştırmada HA kompozit kaplama Ag/Kitosan [9], TiO2 [10], CNT [11], Al203 [12], $\mathrm{ZrO}_{2}$ [13], Kitosan [14] MWNT [15], nano $\mathrm{Y}_{2} \mathrm{O}_{3}$ [16] yapmışlarıdır. HA kaplamanın yanı sıra çalışmada kaplanması düşünülen bir diğer malzeme ise hekzagonal bor nitrürüdür (hBN). hBN en önemli avantajı güçlü kovalent bağ yapısı ile zayıf Vander waals bağlarını bağlar. hBN'nin çok faydalı mükemmel mühendislik özellikleri vardır.

$\mathrm{Bu}$ çalışmada, elektroforetik biriktirme işlem parametreleri (biriktirme zaman, uygulanan voltaj, nano hBN konsantrasyonu) titanyum alaşımı yüzeyine kompozit kaplanması hedeflenmiştir. Çalışma kapsamında yüzey çatlağı olmaksızın nano hBN - HA kompozit kaplama üretimi elde edilerek biyofilim deneyleri öncesi yüzey karakterizasyonu yapılmıştır. Ti alaşımı üzerine kompozit kaplamalar, yüzeysel ve morfolojik incelemeler için yüzey pürüzlülük değerlerinin belirlenmesi ile çalışma tamamlanmıştır. Kaplanan numuneler biyofilim testleri için hazır hale getirilmiştir.

\section{Materyal ve Yöntem}

Çalışma kapsamında EPD kaplama tekniği kullanılmıştır. Toz formundaki hBN ve HA malzemenin Titanyum yüzeyine homojen olarak kaplanması EPD tekniği ile yapılmıştır. EPD kaplama tekniği iki aşamalı gerçekleştirilmiştir. İlk aşamada etanol içinde süspanse edilen yüklü kaplama tozlarının (hBN ve HA) zit yüklü elektrota doğru hareketi gerçekleşmiştir. İkinci aşamada ise tozların (hBN ve HA) zit elektrotda tutunarak Titanyum yüzeyinde kaplaması oluşmuştur. Şekil 1'de EPD yöntemi ile kaplama yöntemi gösterilmiştir.

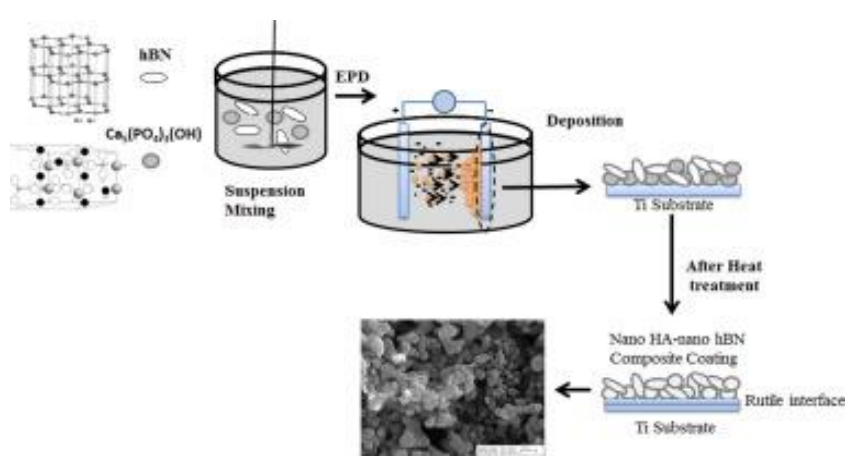
[17]

Şekil 1. EPD Yönteminin Şematik Gösterimi

Hidroksiapatit (HA, Nanotech Advance Technology and Electric Electronic Systems Ltd., Eskişehir, Türkiye) ve hekzagonal bor nitrür (hBN, BORTEK Boron Technologies and Mechatronics Inc.,Eskişehir, Türkiye) kaplama tozları olarak kullanılırken etanol (Absolute, SIGMA-ALDRICH, USA) süspansiyon hazırlamada dağıtıcı ortam olarak kullanılmıştır. A ğırlıkça \% 100 hBN kaplamaları elde edebilmek için hBN citosan (ACROS ORGANICS, moleküler ağırlık, 100,000-300,000), saf su ve etanol karışımında dağıtılmıştır. Kaplamalarda ticari saflıkta titanyum ( $\mathrm{Ti}$, grade 4 , Timet, Türkiye) kullanılmıştır. Tüm kaplamalar doğru akım (direct current, DC) güç kaynağı (BioRAD Power Pac Basic) kullanılarak elektroforetik biriktirme yöntemi (electrophoretic deposition, EPD) ile kaplanmıștır. Kaplamaların 1sı1 işlemleri tüp firında (PROTHERM FURNACE) 
argon atmosferinde (yüksek saflıkta) gerçekleştirilmiştir. Yüzey pürüzlülüğü profilometre (MITUTOYO, SurfTest SJ-401) ile karakterize edilmiştir. SEM görüntüleri DPUİLTEM laboratuvarında bulunan FESEM (alan emisyonlu taramalı elektron mikroskobu) cihazı ile gerçekleştirilmiştir.

HA ve HA-hBN(HA'nın ağırlıkça \% 10 hBN içerir) tozları etanol ortamında manyetik olarak 15 dakika karıştırılarak süspansiyonlar oluşturulmuştur. Süspansiyonlara 1 saat ultrasonik işlem uygulanmıştır. Sonra hacimce $\% 10$ DMF eklenmiş ve $\mathrm{pH}$ değeri 4'e ayarlanmıştır. hBN süspansiyonu için önce kitosan içeren çözelti hazırlanmıştır. Elde edilen çözeltiye ağırlıkça \%0,1 hBN ilave edilip 15 dakika ultrasonik banyoda tutulmuş ve $\mathrm{pH}^{\prime} 13,5$ olarak ayarlanmıştır. Ti levha $1 \times 1 \mathrm{~cm}^{2}$ yüzey alanına sahip olacak şekilde kesilmiş, \#320 ve \#500 grid SiC zımpara kâğıtlarında yüzeyleri benzer özelliklere getirildikten sonra sırasıyla 15 dakika deterjan içeresinde 15 dakika aseton içerisinde ultrasonik banyoda temizlik işlemleri yapılmıştır. Kaplama işlemlerinde kullanılan elektrotlar $\mathrm{Ti}$ plakalardan oluşturulmuştur. Elektrotlar birbirine paralel ve aralarındaki mesafe $10 \mathrm{~mm}$ 'dir. Ti plakaların hazırlanan HA ve HA-hBN kompozit kaplamalar DC 50 volt 1 dakika ile gerçekleştirilmiştir. hBN kaplamalar DC 30 volt 2 dakikada elde edilmiştir. HA, HA$\mathrm{hBN}$ ve $\mathrm{hBN}$ kaplamalar içerdikleri $\mathrm{hBN}$ miktarına göre sırasıyla HB 0.0 , HB 10 ve HB 100.0 olarak kodlanmıştır. HB0.0 ve HB10.0 kodlu kaplamalar argon atmosferinde tüp firında $1^{\circ} \mathrm{C} /$ dak. 1sitma ve soğutma hizı ile $800^{\circ} \mathrm{C}$ ' de 2 saat boyunca 1sıl işleme tabi tutulmuştur. HB 100.0 kodlu kaplamalar ise oda koşullarında sadece kurutulmuş olup isıl işleme tabi tutulmamiştır.

Yüzey pürüzlülükleri profilometre ile 5 farklı yerden (her bir köşeden merkeze doğru ve merkezden dişa doğru) ölçülüştür. Mikro-sertlik deneyleri her numune için üç farklı noktada yapılmış ve ortalama HV değeri deneysel sonuçlar kısmında verilmiştir.

\section{Deneysel Sonuçlar}

Şekil 2-4 'de Ti yüzey kaplaması sonrası yüzey pürüzlülük grafikleri verilmiştir. Yapılan ölçümler sonucunda $\mathrm{HA}+\mathrm{hBN}$ kaplı yüzeyin yüzey pürüzlülük değeri HA kaplama ile yapılan yüzeyden bir miktar yüksek elde edilmiştir. hBN ile yapılan kaplamada ise yüzey pürüzlülügünün en düşük seviyede olduğu ölçülmüştür.

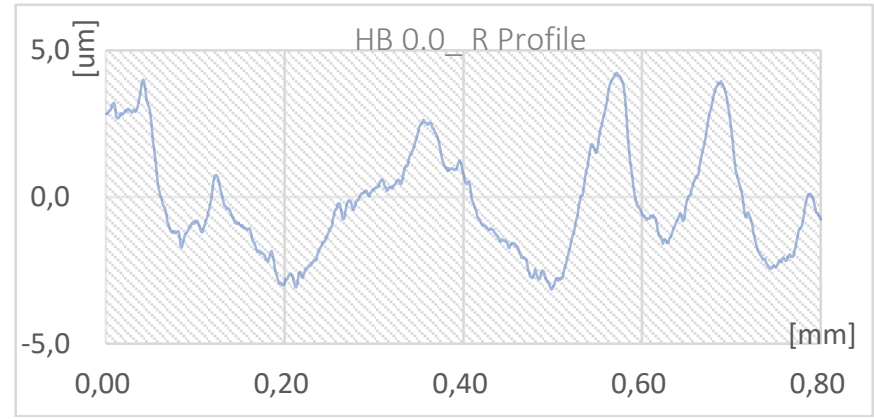

Şekil 2. HB 0.0 numunesinin yüzey pürüzlülük grafiğ $i$

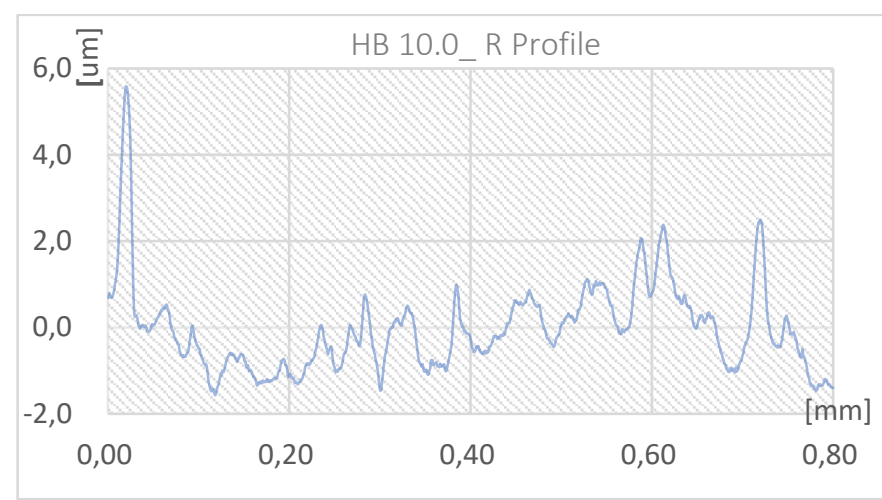

Şekil 3. HB 10.0 numunesinin yüzey pürüzlülük grafiği

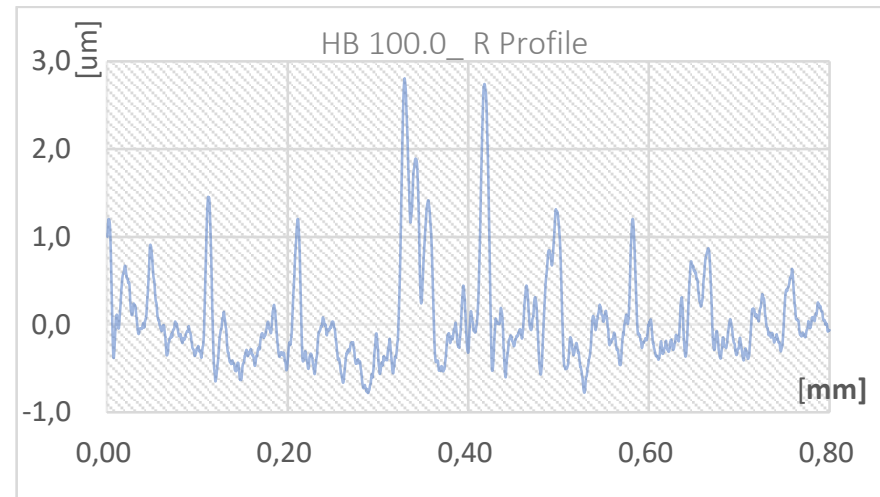

Şekil 4. HB 100.0 numunesinin yüzey pürüzlülük grafiği

Tablo 1'de yüzey kaplama sonrası elde edilen ortalama yüzey pürüzlülük değerleri verilmiştir. 
Tablo 1. Kaplamaların yüzey pürüzlülüğü değerleri

\begin{tabular}{llll}
\hline & HB 0.0 & HB 10.0 & HB 100. \\
\hline $\begin{array}{l}\text { Ortalama } \\
(\boldsymbol{\mu m})\end{array}$ & 1,5475 & 1,6420 & 0,3860 \\
\hline $\begin{array}{l}\text { Standart } \\
\text { sapma }( \pm)\end{array}$ & 0,4401 & 0,1799 & 0,0326 \\
\hline
\end{tabular}

Nano HBN tozlarının kullanıldı $\breve{g} 1$ kaplamalarda yüzey pürüzlülük değerlerinin düştüğü görülmektedir. \%100 HA ve $\% 100 \mathrm{hBN}$ tozaları kullanılarak kaplanan numunelerde sirasiyla en yüksek ve en düşük ortalama yüzey pürüzlülük değeri görülmüştür. Yüzey pürüzlülük değerinin artması ile bakteri oluşumunun arttığ 1 , zittı durumlarda ise azaldığ 1 bilinmektedir.

Tablo 2.'demikro sertlik sonrası elde edilen deney sonuçları verilmiştir.

Tablo 2. Mikro-sertlik değerleri

\begin{tabular}{lccc}
\hline & Ti & HB 100.0 & HB 0.0 \\
\hline $\mathbf{H}$ & 236.29 & 163.19 & 6.73 \\
$\mathbf{V}$ & & &
\end{tabular}

\begin{tabular}{ccc}
\hline Element & Weight $\%$ & Atomic $\%$ \\
\hline C K & 1.51 & 3.90 \\
\hline N K & 1.73 & 3.83 \\
\hline O K & 9.56 & 18.53 \\
\hline P K & 27.52 & 27.55 \\
\hline CaK & 59.69 & 46.19 \\
\hline
\end{tabular}
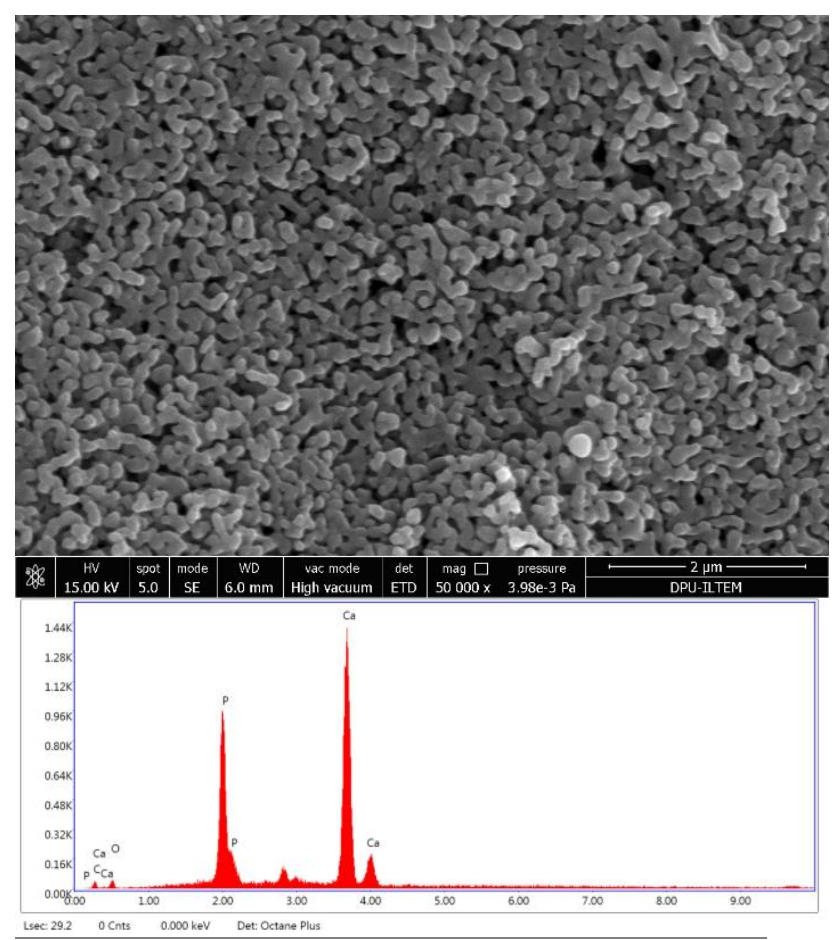

Spekil 6. HB 10.0 numunesinin SEM ve EDX analizi

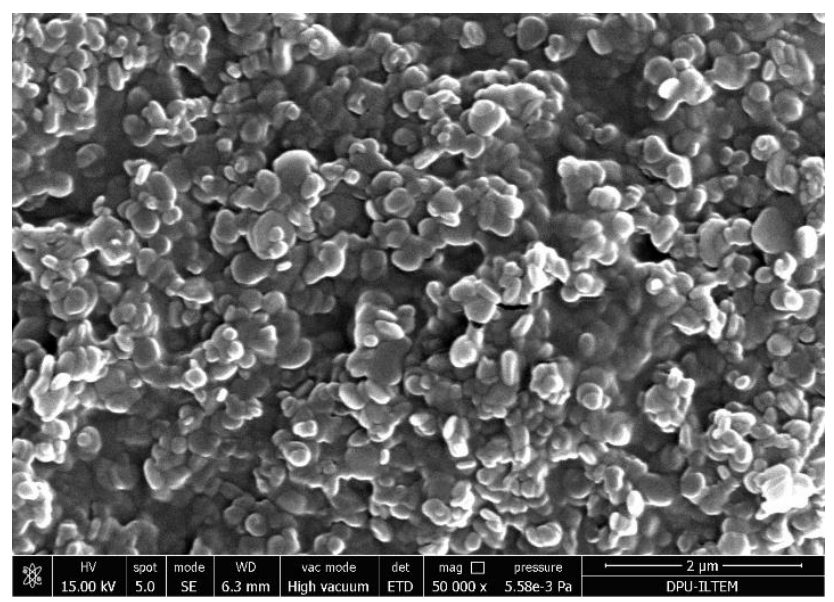

\begin{tabular}{ccc}
\hline Element & Weiaht \% & Atomic \% \\
\hline CK & 1.74 & 4.53 \\
\hline OK & 10.65 & 20.83 \\
\hline PK & 27.18 & 27.46 \\
\hline CaK & 60.43 & 47.19 \\
\hline
\end{tabular}

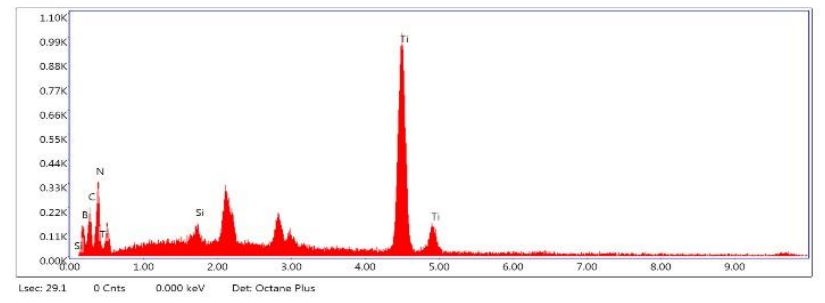

Şekil 5. HB 0.0 numunesinin SEM ve EDX analizi 


\begin{tabular}{ccc}
\hline Element & Weight \% & Atomic \% \\
\hline B K & 16.11 & 37.15 \\
\hline C K & 6.35 & 13.18 \\
\hline N K & 7.10 & 12.64 \\
\hline SiK & 1.04 & 0.92 \\
\hline TiK & 69.40 & 36.11 \\
\hline
\end{tabular}

Şekil 7. HB 100.0 numunesinin SEM ve EDX analizi

Şekil 5-6'da görüldüğü üzere HA içeriğinden kaynaklanan $\mathrm{Ca}$ elementi EDS analizinde görülmektedir. Şekil 7'de ise hBN kaplamdan dolayı $\mathrm{B}$ ve $\mathrm{N}$ elementeleri EDS analiznde görülmüş̧ür.

\section{Sonuçlar ve Tartışma}

Birçok metal alaşım implant uygulamalarında geniş bir şekilde kullanılmaktadır. Bu metal alaşım yüzeylerine kolonize olan bakteriler implanta bağlı olarak enfeksiyon oluşturabilmektedir. $\mathrm{Bu}$ çalışmada implant yüzeyine hidroksiapatit ve nano hexogonal bornitrür ile kaplama yapılarak biyofilim ve buna bağlı enfeksiyon oluşumunu engellemek amaçlı yüzey karakteristiği tayin edilmiştir. Kaplama sonrası yüzeyde oluşan pürüzlülük değişimi, sertlik değişimi ve SEM analizleri gerçekleştirilmiştir. Sonuç olarak dört farklı malzeme (Kaplaması Ti alaşımı, HA, nano $\mathrm{hBN}$, nano $(\mathrm{hBN}+\mathrm{HA}))$ için kaplama ve yüzey karekterizasyonu yapılmıştır. Elde edilen kaplamaların biyofilm oluşturan Staphylococcus aureus bakterisine karşı anti-biyofilm özelliklerini belirlemeye yönelik çalışmalar devam etmektedir. Şimdiye kadar yapılan pek araştırma diş plağı oluşum miktarının, oluşan bu plakaların olgunluğunun ve hareketli çubuk şeklindeki bakterilerin sayısındaki artışın metal yüzeylerin pürüzlülüğünün artması ile doğru orant1lı olduğunu göstermiştir [18]. Amoroso ve ark. 2006, [19] yaptıkları bir çalışmada Porphyromonas gingivalis bakterisinin metal yüzeylere yapışmasının çok daha düz titanyum yüzeylerde $(\mathrm{Ra}=34,57)$ en alt seviyede olduğunu belirlemişlerdir. Benzer sonuçlar in vitro olarak test edilen üç farklı titanyum yüzeyde de Streptococcus mutans, Porphyromonas gingivali ve Fusobacterium nucleatum bakterilerinin yüzey pürüzlülüğü ile yapışma oranının doğru orantılı olduğu gösterilmiştir [20-21]. Benzer örnekler ortopedik implant uygulamalarında ve farklı bakteriler içinde gösterilmiştir [22]. Buna ilave olarak, bor ile kaplı bileşiklerin antibakteriyal özelliği ve bakterilerin biyofilm oluşturma yeteneğinin engellemesi bilinen bir özellik olarak karşımıza çıkmaktadır [23-24]. Göncü ve ark. [17], yaptıkları çalışmada; ağırlıkça \%1 HA süspansiyon ile \% ağırlıkça 0-2.0-5.0-10.0 nanohBN ile karışım hazırlayarak kompozit kaplama yapmışlardır. Yapılan çalışmada Ti yüzeyinde oluşan zeta potansiyeli, kaplama kalınlığı, XRD analizi, SEM analizi ve EDS analizleri yapılmıştır. Çalışmanın sonunda mekanik testlerin yapılması gerektiği vurgulanmıştır. Yüzey pürüzlülük ve sertlik testleri yapılmamıştır. Ayrıca \%100 hBN ile kaplama için bahsi geçen deneyler çalışmada yer almamaktadir.

Bütün bu özellikler dikkate alındığında bu çalışmada hidroksiapatit ve nano hekzagonal bor nitrür kaplı titanyum metallerinin biyofilm oluşturan ve implant kaynaklı enfeksiyonlara neden olan bakterilere karşı etkili olabileceği düşünülmektedir. Fakat bunu doğrulamak ve bu implant olarak düşünülen metallerin diğer özelliklerinin belirlemeye yönelik diğer araştırmalara ihtiyaç duyulmaktadır.

\section{Teşekkür}

Çalışma MMF.A4.18.003'nolu Kırşehir Ahi Evran Üniversitesi BAP projesince desteklenmiştir.

\section{Kaynaklar}

[1] Bosco R., Van Den Beucken J., Leeuwenburgh S., Jansen J., 2012, Surface engineering for bone implants: a trend from passive to active surfaces, Coatings vol. 2 pp. 95.

[2] Narayanan R., Seshadri S.K., Kwon T.Y., Kim K.H. 2008, Calcium phosphate-based coatings on titanium and its alloys, J. Biomed. Mater. Res. B Appl. Biomater. vol. 85B pp. 279.

[3] Javidi M., Javadpour S., Bahrololoom M.E., Ma,J., 2008, Electrophoretic deposition of natural hydroxyapatite on medical grade $316 L$ stainless steel, Mater. Sci. Eng. C Biomim. Supramol. Syst. vol. 28 pp. 1509. 
[4] Iqbal N., Nazir R., Asif, A., Chaudhry A.A., Akram M., Fan G.Y., Akram A., Amin R., Park S.H., Hussain R., 2012, Electrophoretic deposition of PVA coated hydroxyapatite on 316L stainless steel, Curr. Appl. Phys., vol. 12 pp. 755.

[5] Mohseni E., Zalnezhad E., Bushroa A., 2014, Comparative investigation on the adhesion of hydroxyapatite coating on Ti-6Al-4V implant: a review paper, Int. J. Adhes. Adhes. vol.48 pp. 238.

[6] Kim H.W., Koh, Y.H., Li L.H., Lee S., Kim H.E., 2004 Hydroxyapatite coating on titanium substrate with titania buffer layer processed by sol-gel method, Biomaterials, vol. 25 pp. 2533.

[7] Besra L., Liu M., 2007, A review on fundamentals and applications of electrophoretic deposition (EPD), Prog. Mater. Sci. vol. 52 pp. 1 .

[8] Boccaccini A.R., Keim S., Ma R., Li, Y., Zhitomirsky I., 2010, Electrophoretic deposition of biomaterials, J. R. Soc. Interface, vol. 7 pp. 581.

[9] Pang X., Zhitomirsky I., 2008, Electrodeposition ofhydroxyapatite-silver-chitosan nanocomposite coatings, Surf. Coat. Technol., vol. 202 pp. 3815.

[10] Farnoush H., Aldıç G., Çimenoğlu H., 2015 Functionally graded $\mathrm{HA}-\mathrm{TiO} 2$ nanostructured composite coating on Ti$6 A l-4 V$ substrate via electrophoretic deposition, Surf. Coat. Technol., vol. 265 pp. 7.

[11] Lahiri D., Ghosh S., Agarwal A., 2012, Carbon nanotube reinforced hydroxyapatite composite for orthopedic application: a review, Mater. Sci. Eng. C, vol. 32 pp. 1727.

[12] Zhou-Cheng W., Yong-Jin N., Jin-Cong H., 2008 , Fabrication and Characterization of HAp/Al2O3 Composite Coating on Titanium Substrate, Bioinformatics and Biomedical Engineering, ICBBE The 2nd International Conference on, 20081526-1530.

[13] Shojaee P., Afshar A., 2015, Effects of zirconia content on characteristics and corrosion behaviorof hydroxyapatite/ZrO2 biocomposite coatings codeposited by electrodeposition, Surf. Coat. Technol., vol. 262 pp. 166.

[14] Mahmoodi S., Sorkhi L., Farrokhi-Rad M., Shahrabi T.,2013, Electrophoretic deposition of hydroxyapatitechitosan nanocomposite coatings in different alcohols, Surf. Coat.Technol., vol. 216 pp. 106.
[15] Lin C., Han H., Zhang F., Li A., 2008, Electrophoretic deposition of HA/MWNTs composite coating for biomaterial applications, J. Mater. Sci.Mater. Med. vol. 19 pp. 2569.

[16] Parente P., Sanchez-Herencia A.J., Mesa-Galan M.J., Ferrari B., 2013, Functionalizing Ti-surfaces through the EPD of hydroxyapatite/NanoY ${ }_{2} \mathrm{O}_{3}$, J. Phys. Chem., vol. 117 pp. 1600

[17] Göncü Y., Geçgin M., Bakan F., Ay N., 2017, Electrophoretic deposition of hydroxyapatite-hexagonal boron nitride composite coatings on $\mathrm{Ti}$ substrate, Materials Science and Engineering: C, vol.79 pp. 273.

[18] Yeo I. , Kim HY. , LimKS. , Han JS , 2012, Implant surface factors and bacterial adhesion: a review of the literature. Int J Artif Organs., vol. 35:10 pp. 762.

[19] Quirynen M. , Van Der Mei HC. , Bollen CM., at al., 1993, An in vivo study of the influence of the surface roughness of implants on the microbiology of supra-and subgingival plaque. J Dent Res., vol. 72:9 pp. 1304.

[20] Amoroso PF, Adams RJ, Waters MG, Williams DW., 2006, Titanium surface modification and its effect on the adherence of Porphyromonas gingivalis: an in vitro study. Clin Oral Implants Res., vol. 17:6 pp. 633.

[21] Badihi Hauslich L, Sela MN, Steinberg D, Rosen G, Kohavi D., 2011, The adhesion of oral bacteria to modified titanium surfaces: role of plasma proteins and electrostatic forces. Clin Oral Implants Res., Dec 13.

[22] Ribeiro M. , Monteiro F.J., Ferraz M.P., 2012, Infection of orthopedic implants with emphasis on bacterial adhesion process and techniques used in studying bacterial-material interactions. Biomatter. Oct 1; vol. 2(4): pp. 176.

[23] Ba1ley P. J., Cousins G., Snow, G. A. , White A. J. , 1980, Boron-Containing Antibacterial Agents: Effects on Growth and Morphology of Bacteria Under Various Culture Conditions. Antimicrobil Agents And Chemotherapy, Apr. pp. 549.

[24] Sayin Z, Ucan US, Sakmanoglu A., 2016, Antibacterial and Antibiofilm Effects of Boron on Different Bacteria. Biol Trace Elem Res. vol. 173(1) pp. 241. 


\section{Determination of the effect of nano- implants coating with nano hBN - Ha for biofilm prevent on surface characteristics}

\section{Extended abstract}

It is widely used in many metal alloy implant applications. Bacteria that colonize these metal alloy surfaces can cause infection depending on the implant. In this study, the surface characteristic of biofilm and associated infection was determined by coating with hydroxyapatite and nano hexogonal bornitride on the implant surface. Roughness change, hardness change and SEM analysis on the surface after coating were performed. The relevance of the bio-surface obtained to the Staphylococcus aureus bacteria continues to be investigated.

Ti alloy surface has been applied with EPM method in different rates $h B N$ and $H A$ coating. Hardnesses were measured after coating. Surface characteristics were investigated by measurements with SEM. In addition, surface roughness measurements of coating surfaces were made.
Considering all these features, it is thought that in this study, hydroxyapatite and nano hexagonal boron nitride coated titanium metals may be effective against bacteria that form biofilm and cause implantborne infections. However, other research is needed to confirm this and to determine other properties of metals considered as implants.

Keywords: biofilm, coating, implant, Ti alloy 